\title{
5. DOCUMENTATION
}

(Committee of the Executive Committee)

President: J. B. Sykes.

Vice-President: K. F. Ogorodnikov.

No Organizing Committee.

\section{Secondary publications}

Fricke and Henn report that Astronomy and Astrophysics Abstracts $(A A A)$ has continued to be published regularly in semi-annual volumes, and appears from all the available reviews in journals to be entirely in accordance with the needs of astronomers. No immediate changes are envisaged, but the classification scheme is open to revision where necessary; suggestions from users are welcomed.

In Trans. IAU, XIVB, p. 256, a recommendation is made that $A A A$ abstract numbers should be used as a very brief form of bibliographical reference in the Reports on Astronomy.

Bulletin Signalétique, including section 120 (astronomy, space physics, and geophysics), has been available since the beginning of 1972 on microfiche covering three months' issues at a time.

\section{ICSU Abstracting Board}

The work of the ICSU AB has been described in IAU Inf. Bull., No. 27, pp. 20-21. I attended, as representative of the IAU, the meetings of the Board in 1970, 1971 and 1972. I also served as chairman of the statutes and by-laws committee, and until 1971 as a member of the planning and steering committee.

The Board's working group in astronomy held a meeting in 1971, which has been reported in IAU Inf. Bull., No. 27, p. 22.

ICSU AB has played a prominent role in the UNISIST study of a world science information system. This study, of which a report was published in both full and abridged forms by UNESCO in 1971, showed that such a system is both feasible and necessary. At an inter-governmental meeting in October 1971, which I attended as a member of the ICSU AB delegation, a final report was adopted, which has been published by UNESCO (1972). The implementation of the report is now proceeding.

Two results of the UNISIST study that are of general interest are the production of a reference manual for the preparation of machine-readable bibliographic descriptions, and the establishment of an International Seriais Data Service to maintain control of the constantly changing population of periodicals and provide information about them. The International Standard Serial Numbers allocated by this service are already appearing on some periodicals.

ICSU AB has published a small folder giving details of the principal abstracting services in physics, and a similar publication for astronomy is being investigated.

\section{Current-awareness and retrieval services}

Feuillebois reports that Bulletin Signalétique section 120 (see above) has been available on magnetic tape since January 1971, with current-awareness notification and on-line searching since January 1972. A French thesaurus of terms for use in retrieval is now in course of preparation. The Paris Observatory has continued its regular current-awareness service on cards to over twenty other observatories.

The American Institute of Physics published in 1971 The AIP Program for Physics Information ( $A A A$ 07.002.036), describing a wide range of publications and services planned and available. Similar services are being developed by INSPEC in the U.K.

The MiniPrint Corporation of Metuchen, New Jersey, has issued a reduced-scale reprint of the 
International Catalogue of Scientific Literature. E. Astronomy. Nos. 1-14. Literature of 1901-15 (a continuation of the Royal Society Catalogue of Scientific Papers, 1800-1900).

The ESRO Space Documentation Service, mentioned in Trans. IAU, XIVA, p. 12, has introduced access to the contents of Scientific and Technical Aerospace Reports and International Aerospace Abstracts ( 600000 documents) by means of search requests submitted from remote terminals at national documentation centres.

\section{Information use}

Meadows and O'Connor (University of Leicester, U.K.) have published further reports on their studies of information use and needs for astronomy: 'Bibliographical statistics as a guide to growth points in science', 1971, Science Studies 1 (1), 95-99; 'Library provision in astronomy and space science', 1970, and 'A survey in depth of a selected information field (astronomy and astrophysics)', 1971 , both reports issued by the Office for Scientific and Technical Information, London.

\section{Publication style}

Seven members replied to my enquiry of October 1971 about the views expressed in the report of Commission 36 meeting in Brighton (Trans. IAU, XIVB, pp. 209-210). The results have been summarized to the President of that Commission, Dr. Thomas. The general opinion was that, although cheaper publications are of course to be welcomed, quality of production of definitive proceedings is important, both as regards preservation and for the psychological reason that a well-produced book is a pleasure and an incentive to readers.

\section{Bibliographies}

Kemp has published Astronomy and Astrophysics: $A$ Bibliographical Guide (AAA 03.003.035).

Kleczek et al. have published $A$ general bibliography of solar prominence research 1880-1970, 1972, publication 53, Astronomical Institute of the Czechoslovak Academy of Sciences, Prague.

Lavrova has continued to compile bibliographies of books and papers on the history of astronomy for Commission 41.

Rosenberg and C. Jansen have published two instalments of the Bibliography of non-commercial publications of observatories and astronomical societies (AAA 05.002.044). A third instalment is to follow. This work has had financial support from the International Federation of Library Associations. Rosenberg suggests that these non-commercial publications are tending to become restricted to data and routine observations, and that series consisting only of reprints from well-known journals should be replaced by regularly distributed lists of reprints available.

\section{Librarianship}

Feuillebois reports that the Astronomical Libraries sub-section of the International Federation of Library Associations has met again in 1971, and is interested in maintaining close collaboration with the IAU. She also says that the input is being prepared for an automated union catalogue of periodicals in French observatory libraries, which will contain much information and allow various types of print-out. An adapted Marc II format is used, with a view to subsequent international exchange of tapes.

American observatory librarians held a meeting in June 1972 under Weigel's chairmanship, and are likely to participate in a proposed physics/astronomy/mathematics division of the U.S. Special Libraries Association. A directory of astronomical librarians in the U.S. has been drafted. A further meeting is planned for June 1973, at which societies with publication programmes will be represented. Heintz will probably attend on behalf of the IAU. He has recently made contact with the American Astronomical Society concerning the listing of institutes and publications.

Grassi Conti has continued her work on books of the 15th and 16th century in European observatory libraries, and hopes to publish a first draft of the union catalogue in 1973 . Nearly 40 observatories have contributed information on some 1500 works.

G. Johns has compiled checklists of the literature in the Ernst Zinner collection, San Diego 
(AAA 05.003.052). Prof. Zinner was a member of Commission 5 from 1955 until his death in August 1970.

\section{Transliteration}

The transliteration of the Russian alphabet recommended by Commission 5 (Trans. IAU, XIVB, p. 87) has been adopted by the Union.

The UNISIST reference manual mentioned above includes proposals for the transliteration of accented letters in various languages to allow machine readability.

\section{Abbreviations}

Another product of the UNISIST investigations is the International List of Periodical Title Abbreviations (see IAU Inf. Bull., No. 26, p. 20). This is comprehensive, and might serve as a basis to be recommended in the next edition of the IAU Style Book. On the other hand, Fricke and Henn argue that the $A A A$ abbreviations list has proved easy to use and satisfactory, and should therefore be more widely adopted in astronomy.

Feuillebois suggests that the somewhat arbitrary list of abbreviations for organizations etc. in the Style Book could be replaced by a reference to the extensive listing in Kemp's bibliography (see above). This would no doubt need regular updating.

\section{Numerical data}

I have been a member of the IAU Working Group on Numerical Data (Trans. IAU, XIVB, p. 245), of which Wilkins is the chairman, and contributed information in the field of documentation.

\section{Symbols}

Eleven members replied to my enquiry of October 1971 about the abbreviation for the astronomical unit. Several suggestions were made, but the general opinion was that the name is firmly established and the symbols UA and AU should both be retained.

\section{Classification}

There is not much progress to report as regards the attainment of a classification scheme common to more than one abstracting service in astronomy, partly because the various schemes used at present have not necessarily reached their final form.

After discussions at the Brighton meeting, a working group was set up jointly with the Fédération Internationale de la Documentation as managers of the Universal Decimal Classification, to investigate further the revision of the UDC schedules for astronomy. The members of the group are Kemp (chairman), Lavrova, Mein, Wilkins, and a representative of the German Standards Association. (Mein wishes to be replaced by P. Lantos (Meudon) in 1973.)

Kemp reports that there may have to be a fairly general rearrangement of the schedules, although the order of the principal subdivisions is agreed. A classification making use of 'facets' (type of body, property studied, etc.) would be helpful, but is difficult to construct. The aim is to provide a classification simultaneously useful for abstracts, indexes, library arrangement, and computerized retrieval of information.

\section{World list of observatories etc.}

Following the joint meeting in Brighton(Trans. IAU, XIVB, p. 89), I corresponded with chairmen of National Committees for Astronomy, but the response was poor. It may be possible to make progress in further discussions in Sydney, but the most useful procedure may be to request directors of observatories to include the appropriate information in their annual reports or in separate leaflets sent out together with other publications. According to IAU Inf. Bull., No. 28, p. 11, the Kitt Peak National Observatory has compiled a loose-leaf 'Users' Book' with brief descriptions of the equipment, programmes, etc. I hope that other observatories will follow this example. 
Priorities

The General Secretary has asked that each Commission's report should include a short mention of priorities and expected developments in its field, for discussion at a meeting of the Commission in Sydney. I suggest the following points.

(1) Advancement of work on unified classification schemes and thesauri.

(2) Closer relationships between the IAU and editors of primary journals in astronomy, perhaps through the formation of an association of the latter (similar to those already existing in some other scientific disciplines). This would provide a means of discussing many problems: uniform style, notation, abbreviations, refereeing, and publication policy, e.g. as regards extensive data tabulations.

J. B. SYKES

President of the Commission

\section{ADDENDUM}

The following contribution describing the work of VINITI (the Soviet Institute of Scientific and Technical Information) was received too late to be incorporated in the main report.

Referativnyj zhurnal continued to appear for various subject fields, including Astronomy, Geodesy and aerial surveying, and Space research with a total of about 17500 abstracts plus annual indexes. The subject classification system is being further revised and improved in order to remain in line with the current state of development of astronomy. The list of publications examined by Re erativnyj zhurnal has been revised and will be republished at the start of 1973.

The review series Itogi nauki (Trans. IAU, XIVB, p. 86) has continued with Physics of the Sun (1970), Terrestrial planets (1970), Acceleration processes in space (1972) and Physics and stellar evolution (1972).

The current-awareness service (Trans. IAU, XIVB, p. 87) is still under consideration, because of its interconnection with general changes in the working methods of VINITI. 